Editorial

\title{
Perspective and expectation for IRATJ
}

\section{Editorial}

I'm very glad to see the first issue of International Robotics and Automation Journal (IRATJ) at this age of man-machine coexistence, at the time of well-development of information and image technology, technicalization and unmanned technology will surely be the inevitable trend of development of such industries as industry, medical treatment, service, and environmental safety and maintenance of next generation, which will lead to the polarization of industrial added value, and change the commercial and manipulation models of various industries and transform our life patterns thoroughly. Undoubtedly, Robotics and Automation as the main roles leading the age of manmachine coexistence. I still remember that, when the concept of "robot" was put forward 20-30 years ago, most people showed doubts and hesitation on the work of robots replacing part of human beings' work. At that time, the development of robots was mostly built on the basis of fundamental research and development and rudiment structure conducted by the academic circle and a few research institutions, but for more than 20 years, with the rapid development of intelligence combination of IC and photoelectric elements and the great promotion of the function and efficiency of precision machinery, robots have developed to the degree of implementing high-precision medical work such as minimally invasive surgery. The issue of IRATJ provides the latest development tendency and progress of relevant robot field and explains how to relearn and create more intelligent working results in the time of man-machine coexistence, through the progress and results of various latest research and development technologies in such aspects as robot and automation provided by the scholars, experts and researchers in this field, IRATJ provides a multiple and open platform, with the purpose of promoting or facilitating all the workers in this
Volume 2 Issue I - 2017

Jen Fin Lin

Department of Mechanical Engineering, National Cheng Kung University, Taiwan

Correspondence: Department of Mechanical Engineering, National Cheng Kung University, Taiwan,

Email jflin@mail.ncku.edu.tw

Received: February 08, 2017 | Published: February 23, 2017

filed across the work to have more communication and cross-field cooperation and of the implementation of research and development results on various application objects, IRATJ adopts the means of Peer-reviewed, to welcome original paper contribution on multiple fields of man-machine interface, operation, automation, sensing and actuation, mechanical power transmission, mechanism and statics/ dynamics, electro-mechanical integration and control, materials, and micro robot, so as to let the journals that conform to modern scientific and technological development to become high-quality journals with indicating significance and informatively. I present the deepest anticipation and blessings.

\section{Acknowledgements}

None.

\section{Conflict of interest}

The author declares no conflict of interest. 